\title{
Uso de Integração Numérica em Problemas de Engenharia
}

\author{
Augusto Giacchini Kloth* Olga Harumi Saito \\ Departamento Acadêmico de Matemática, UTFPR \\ 80230-901, Curitiba, PR \\ E-mail: agkkloth@hotmail.com, harumi@utfpr.edu.br.
}

\section{RESUMO}

O objetivo deste trabalho é apresentar um estudo inicial do uso de integração numérica na resolução de problemas aplicados à engenharia. Dentre os métodos existentes, serão apresentados os métodos dos Trapézios e de Simpson na resolução de um problema aplicado. O problema em questão é o cálculo da resposta em um transdutor quando o transdutor sofre uma onda de choque proveniente de uma explosão, em determinado tempo. Ainda, será analisado o erro cometido na utilização destes métodos.

Palavras-chave: integração numérica, método dos Trapézios, método de Simpson, onda de choque

\section{Integração}

O cálculo utilizando-se de elementos infinitesimais, semelhante ao que se conhece hoje por Cálculo Diferencial e Integral, já era utilizado por matemáticos da Grécia Antiga, e desenvolveuse ao longo do tempo, de forma a tornar-se o que existe hoje. O conceito de integral definida proposto por [1] pode ser dado através do limite expresso em (1), sendo $f$ contínua no intervalo $[a, b]$, dividido em partições de tamanho $\Delta\left(x_{i}\right)$.

$$
\int_{a}^{b} f(x) d x=\lim _{\Delta\left(x_{i}\right) \rightarrow 0}\left[\sum_{i=1}^{n} f\left(c_{i}\right) \Delta\left(x_{i}\right)\right]=F(b)-F(a)
$$

Pelo Teorema Fundamental do Cálculo, $F(x)$ é tal que $F^{\prime}(x)=f(x) . F(x)$ é a primitiva ou antiderivada de $f(x)$.

\section{Integração Numérica}

A integração numérica é apresentada por [1] e [3] e consiste em aproximar a função a ser integrada por funções cuja integral seja conhecida. Este processo é notável desde o século XVIII como alternativa ao cálculo da primitiva. A integração numérica pode ser chamada de quadratura, pois é um método que mede a área sob uma curva ao traçá-la em papel milimetrado e contar os quadrados sob esta.

As Fórmulas de Newton-Cotes para integração numérica são identificadas por trabalharem com $N$ pontos igualmente espaçados dentro do intervalo de integração. Dentre estas, os métodos dos Trapézios e de Simpson interpolam um polinômio de grau $N-1$ pelos pontos dados, polinômio este que será efetivamente integrado.

Fazendo-se $N=2$ na situação anteriormente expressa, tem-se o método dos Trapézios, que aproxima a função $f(x)$ por uma função linear, cujo gráfico é uma reta. O método de Simpson

\footnotetext{
*Bolsista de Iniciação Científica PICME/CNPq
} 
é obtido ao impor $N=3$. Neste caso, a função $f(x)$ é aproximada por um polinômio $P(x)$ de grau 2. A Figura 1 ilustra estas duas situações.

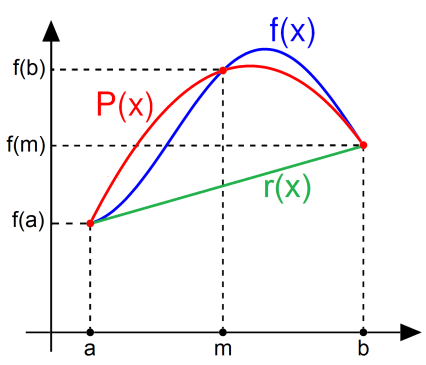

Figura 1: Função $f(x)$ aproximada pelo método 1-Trapézio $(r(x))$ e pelo método 1-Simpson $(P(x))$ - Fonte: adaptado de [4].

Utilizando-se da fórmula da Geometria Plana para cálculo da área do trapézio, pode-se aproximar a integral definida de $f(x)$ pelo método dos Trapézios, dando origem à equação (2).

$$
\int_{a}^{b} f(x) d x \approx \frac{h(f(a)+f(b))}{2}, \quad h=b-a
$$

Já para construir o polinômio de grau 2 do método de Simpson são necessários três pontos: $(a, f(a)),(m, f(m))$ e $(b, f(b))$, sendo $m$ ponto médio de $a$ e $b$. A integral aproximada pelo método de Simpson é dada pela equação (3). Para o método de Simpson, tem-se $h=m-a$.

$$
\int_{a}^{b} f(x) d x \approx \frac{h}{3}(f(a)+4 f(m)+f(b))
$$

É possível, ainda, calcular o erro máximo cometido ao calcular uma integral definida pelos métodos dos Trapézios e de Simpson, dado respectivamente por (4).

$$
E_{\text {trap }}=\frac{h^{3}}{12} M \quad E_{\text {simp }}=\frac{h^{5}}{90} N
$$

M é o máximo valor de $\left|f^{\prime \prime}(\zeta)\right|$ e $\mathrm{N}$ é o máximo valor de $\left|f^{(4)}(\zeta)\right|$, com $a \leq \zeta \leq b$.

Em ambos os métodos, o intervalo inicial $[a, b]$ pode ser dividido em subintervalos, de forma a aumentar a precisão do resultado. Para obter o valor aproximado da integral, basta somar os valores obtidos para cada subintervalo. Cada erro máximo local é obtido através de (4), desde que utilizado o $h$ do subintervalo correspondente.

\section{Aplicação e Resultados}

$\mathrm{Na}$ área de Engenharia é comum deparar-se com integrais cujo melhor método de resolução é através de integração numérica. Por exemplo, [2] apresenta o problema de uma onda de choque proveniente de uma explosão, que tem sua resposta em um transdutor dada por: $F(t)=$ $\frac{8}{\pi} e^{-t} I(a)$, para $t \geq a$. O valor $I(a)$ é dado por:

$$
I(a)=\int_{1}^{2} \frac{e^{a x}}{x} d x .
$$

Calculou-se I(1) através de programação da calculadora HP 50g, obtendo os valores da Tabela 1, que traz os resultados utilizando os dois métodos de integração e variando o número de partições do intervalo $N_{\text {par }}$. O valor $E$ é o erro máximo local, calculado por meio de (4).

A Figura 2 mostra o gráfico de $F(t)$ com os valores de $I(1)$ obtidos na Tabela 1. Em verde é mostrado $F(t)$ quando $I(1)$ é obtido através do método dos Trapézios com $N_{p a r}=1$. Já em violeta, é o resultado obtido quando utiliza-se o método de Simpson com $N_{p a r}=1$. Utilizando 
os outros valores de $I(1)$ apresentados na tabela encontrou-se comportamento próximo ao de Simpson, destacado em violeta no gráfico.

Tabela 1: Apresentação dos resultados de $I(1)$ e erros associados

\begin{tabular}{|c|c|c|c|c|c|c|c|c|}
\hline & \multicolumn{3}{|c|}{ Método dos Trapézios } & \multicolumn{3}{c|}{ Método de Simpson } \\
\hline$N_{\text {par }}$ & 1 & 3 & 6 & 9 & 1 & 2 & 3 & 4 \\
\hline$I(1)$ & 3.20641 & 3.07612 & 3.06339 & 3.06102 & 3.06066 & 3.05924 & 3.05914 & 3.05913 \\
\hline$E$ & 0.22652 & 0.02517 & 0.00629 & 0.00280 & 0.00849 & 0.00053 & 0.00011 & 0.00003 \\
\hline
\end{tabular}

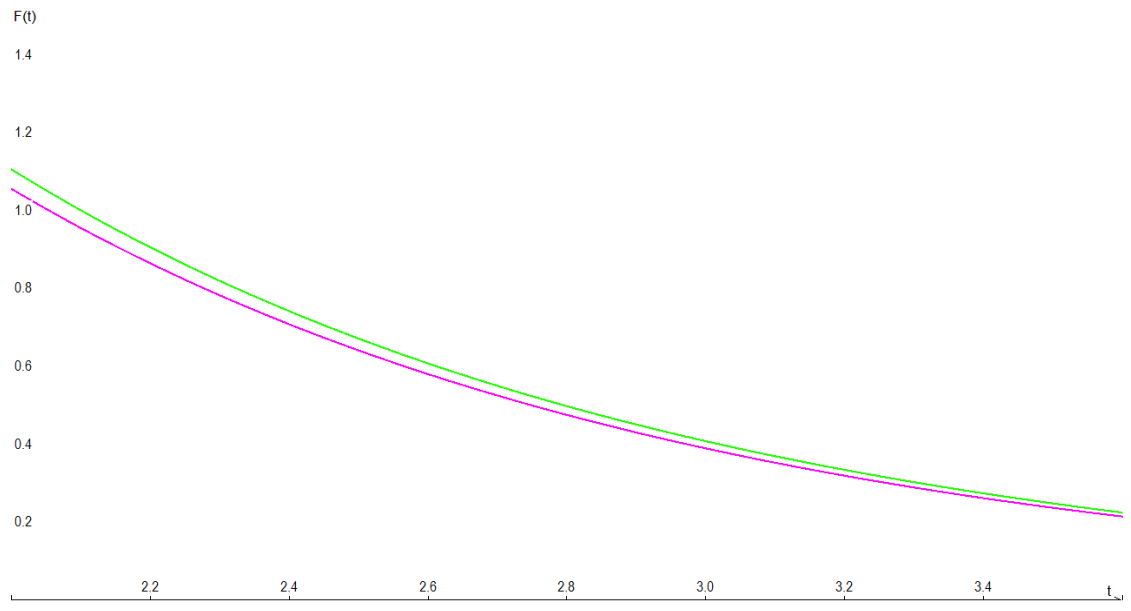

Figura 2: Gráfico de $F(t)$ para diferentes valores de $I(1)$ - Fonte: o autor, gerado pelo Winplot.

\section{Conclusões}

Em relação ao problema apresentado, utilizando o mesmo número de partições de intervalo, o método de Simpson mostrou maior precisão em relação ao método dos Trapézios. O gráfico da Figura 2 corrobora esta situação, evidenciando a diferença dos resultados obtidos pelos diferentes métodos. Analisando a Tabela 1, por sua vez, nota-se que a ordem do erro máximo cometido por 6-Trapézios é a mesma de 1-Simpson.

Assim, nota-se a importância que estas ferramentas desempenham em aplicações da área de Engenharia, como a exemplificada. Estudos com outros métodos de integração numérica podem ser realizados a determinadas situações-problema.

\section{Referências}

[1] GAELZER, Rudi. "Integração Numérica". Disponível on-line em: http://minerva.ufpel.edu.br/ ${ }^{\sim}$ rudi/grad/ModComp/MetNum/html/Apostilach3.html. Acesso em 24 set. 2013.

[2] MONTEIRO, Maria T. T. "Métodos Numéricos: exercícios resolvidos aplicados à Engenharia e outras Ciências". Disponível on-line em: http://repositorium.sdum.uminho.pt/bitstream/1822/14965/6/livro_mn.pdf. Acesso em 06 jul. 2013.

[3] RUGGIERO, Márcia A. Gomes; LOPES, Vera Lúcia da Rocha. "Cálculo numérico: aspectos teóricos e computacionais". 2. ed. São Paulo: Makron, 1997.

[4] Wikimedia. Disponível on-line em: http://upload.wikimedia.org/wikipedia/commons/1/13 /Simpsons_method_illustration.png. Acesso em 01 jul. 2013. 